\title{
UPGRADING OF DISCHARGE RATES USING GEOPHYSICAL AND STRUCTURAL ANALYSIS: SANGEMIL SPA (CENTRAL PORTUGAL)
}

\author{
Dias, J.M.M. ${ }^{1}$, Figueiredo, F.P.O. ${ }^{1}$, Morais, M.J.F. ${ }^{2}$ \\ Portugal Ferreira, M.R. ${ }^{2}$ \& $\underline{\text { Senos Matias, M.J. }}{ }^{3}$ \\ ${ }^{1}$ Departamento de Ciências da Terra, Universidade de Coimbra, Portugal, (fpedro@ci.uc.pt). \\ ${ }^{2}$ Instituto de Investigação da Água, Universidade de Coimbra, Portugal, (mmorais@ci.uc.pt). \\ ${ }^{3}$ Departamento de Geociências, Universidade de Aveiro, Portugal, (mmatias@geo.ua.pt).
}

KEYWORDS: Hydrogeology, thermal water, dipole-dipole array and resistivity imaging.

\section{INTRODUCTION}

Sangemil spa area is located $16 \mathrm{~km}$ south of Viseu, Central Portugal, near the Dão river. The productive wells, F1 and F2 are located in the alluvial plain of the river and have been threatened by the river floods (Fig. 1).

In order to locate new production wells, out of the alluvial plain and close to the spa unit the surrounding geological structure was surveyed. The proposed structural model claimed for a geophysical survey with two profiles P1 and P2 (Fig. 1) using dipole-dipole array. Taking into account the results obtained, three new wells, HDN1, HDN2 and HDN3 (Fig. 1) have been drilled ( 85 to $112 \mathrm{~m}$ deep). The field measurements of conductivity, temperature, $\mathrm{pH}$ and yield are discussed in conjunction with the geophysical results.

\section{GEOLOGY AND HYDROGEOLOGY}

The mountainous region of Northern and Central Portugal has a significative number of hydrothermal low enthalpy resources. The thermal water springs are mainly encased in fractured granites of the Hesperic Massif. This massif was cut by large and deep faults during the Hercynian cicle. Some of them have been reactivated during Alpine orogeny and lead to extensive deep circulation of meteoric water and also stand as the ascending branchs of the thermal circuits.

It is found that, although in association with regional faults, the exsurgences are subordinated to discrete channels along secondary transverse fractures. Those structures are defined by structural analysis and geophysical methods (Portugal Ferreira et al., 1984).

At the Sangemil thermal area the outcrops are predominantly made of coarse to medium porphyritic calc-alkaline granites with a late-Hercynian emplacement (Morais, 1990).

Geological and structural mapping (Fig. 1) suggest an interpretative frame that explains the thermal water natural discharge and supports, together with geophysical data, the location of new prospecting wells. So it is possible to say that the thermal waters ascend along the crossings (tectonic nodes) between a major fault called Sangemil thermal fault, N60 ${ }^{\circ}$, subvertical (10$15 \mathrm{~m}$ width), and faults $\mathrm{N} 5^{\circ} \mathrm{E} ; 75^{\circ} \mathrm{E}$ and $\mathrm{N} 5^{\circ} \mathrm{E} ; 75^{\circ} \mathrm{W}$ forming preferential channels plunging NNE and NNW, as it can be seen in the interpretative structural profile P1 (Fig. 2), (I.I.A., 1998).

With a temperature of $49^{\circ} \mathrm{C}$ and low mineralization (TSD $=475 \mathrm{mg} / \mathrm{l}$ ), the Sangemil mineral water is alkaline $(\mathrm{pH}=8.5)$, sodium bicarbonated, with high contents of silica, chloride and fluoride. The low redox potential allows the presence of reduced species of sulphur exhibited by $\mathrm{H}_{2} \mathrm{~S}$ smell. They are traditionally used for medical purposes (Morais, 1990). 


\section{GEOPHYSICAL SURVEY}

Owing to the expected high electrical contrast between the granitic rocks and the fractures, with the circulation of high conductive thermal water, two dipole-dipole resistivity profiles, P1 and P2 (Fig. 1) were carried out using an electrode spacing of $7.5 \mathrm{~m}$ and $n$ values ranging for 1 to 12 . The length and pseudodepth of these profiles were limited by topography, the Dão river valley and the local buildings.

In these geostructrural complex area, layered solutions must not be expected and interpreted. In fact, it is realistic to look for 2D interpretation models, with vertical structures, as it is suggested by the data field sections (Fig. 3 and Fig. 4). Therefore resistivity data were inverted using the RES2DINV software (Loke, 1999). The final interpretation shows a good correlation between the local fractured granitic rocks (Fig. 2), and the low resistivity zones (i) and (ii) in profile P1, with values of 117 ohm.m (Fig. 3) and (iii) in profile P2, with values of 474 ohm.m (Fig. 4).

\section{FINAL REMARKS}

Based on the geostructural and geophysical survey the three new wells, HDN1, HDN2 and HDN3 were located. The loggings for conductivity, temperature, $\mathrm{pH}$ and yield of these wells (Bajouco, 1999) are shown in Fig. 5.

The wells HDN1 and HDN2 were plenty fully success with yields of 12 and 1.8 1/s, respectively. The extracted water has physical and chemical properties within the range of the Sangemil thermal mineral water type. At a favorable structural setting and with the lowest resistivity values, those prospecting sites had a high potencial for thermal water.

Although productive, the well HDN3 $(2.5 \mathrm{l} / \mathrm{s})$ did not produce water with the required therapeutic quality, but it is useful for another uses in the spa.

\section{ACKNOWLEDGEMENTS}

The authors would like to thank the Tondela Town Council (C.M. Tondela), HidroNorte, Lda. and Beira Termas, Gestão e Equipamentos Termais, S.A..

\section{REFERENCES}

Bajouco, P.S.M.P. (1999). Novas sondagens nas Caldas de Sangemil. Relatório de estágio para a Ordem dos Engenheiros, Coimbra, 61 p.

Instituto de Investigação da Água, U.C. (I.I.A.) (1998). Estudos para novas sondagens nas Caldas de Sangemil. Relatório interno, Coimbra, 20 p.

Portugal Ferreira, M.R., Carvalho, J.N. \& Mendonça, J.L. (1984). Águas minerais na Zona Centro Ibérica (Sector de Portugal): Metodologia. Tipologias. I Congreso Españhol de Geologia, Tomo IV, pp. 317-330, A. Españhola de Geológos. Madrid, Espanha.

Loke, M.H. (1999). Electrical imaging surveys for environmental and engineering studies. A practical guide to 2-D and 3-D surveys, 57 p. (http://www.abem.se).

Morais, M.J.F. (1990). Termas de Sangemil - Um estudo hidrogeológico. Dissertação de Provas de Aptidão Pedagógica e Capacidade Científica, Universidade de Coimbra, 214 p. 


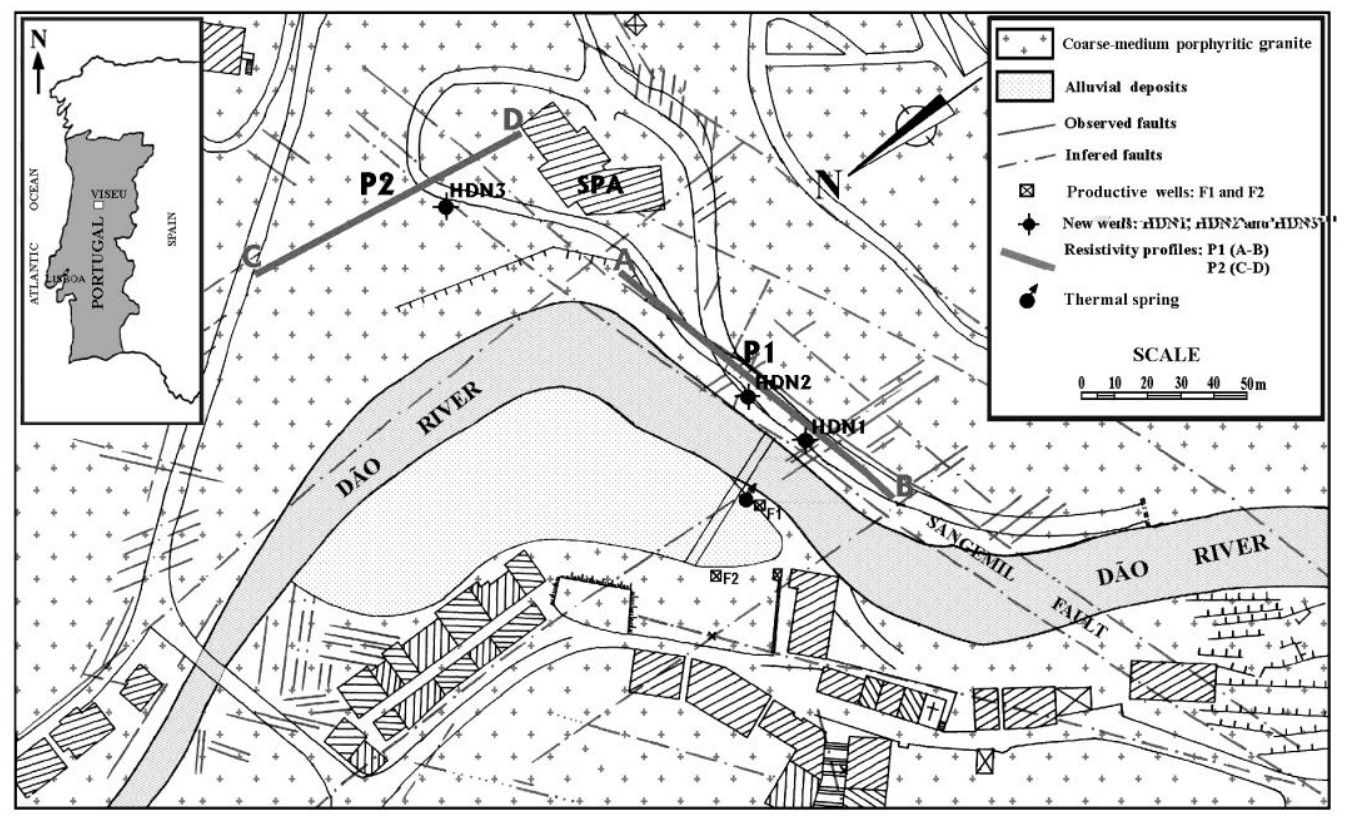

Fig. 1 - Location of Sangemil spa, geological map, productive wells (F1 and F2) and new wells (HDN1, HDN2 and HDN3) and electrical resistivity profiles P1 (A-B) and P2 (C-D).

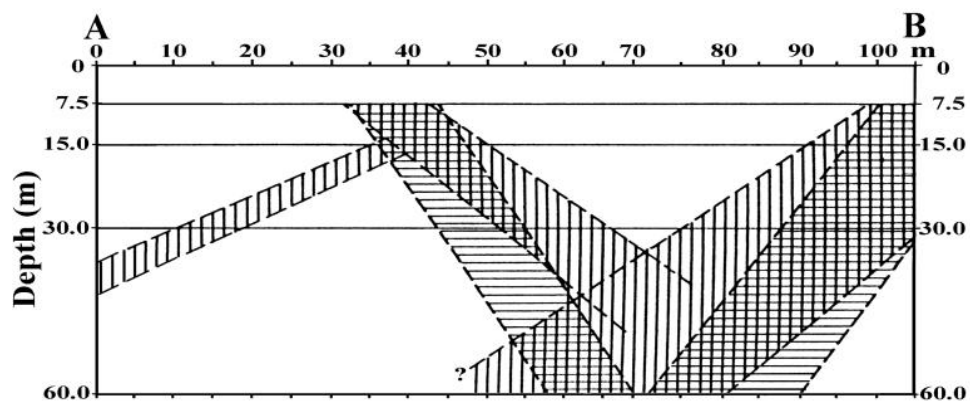

Fig.2 - Interpretative structural profile P1.
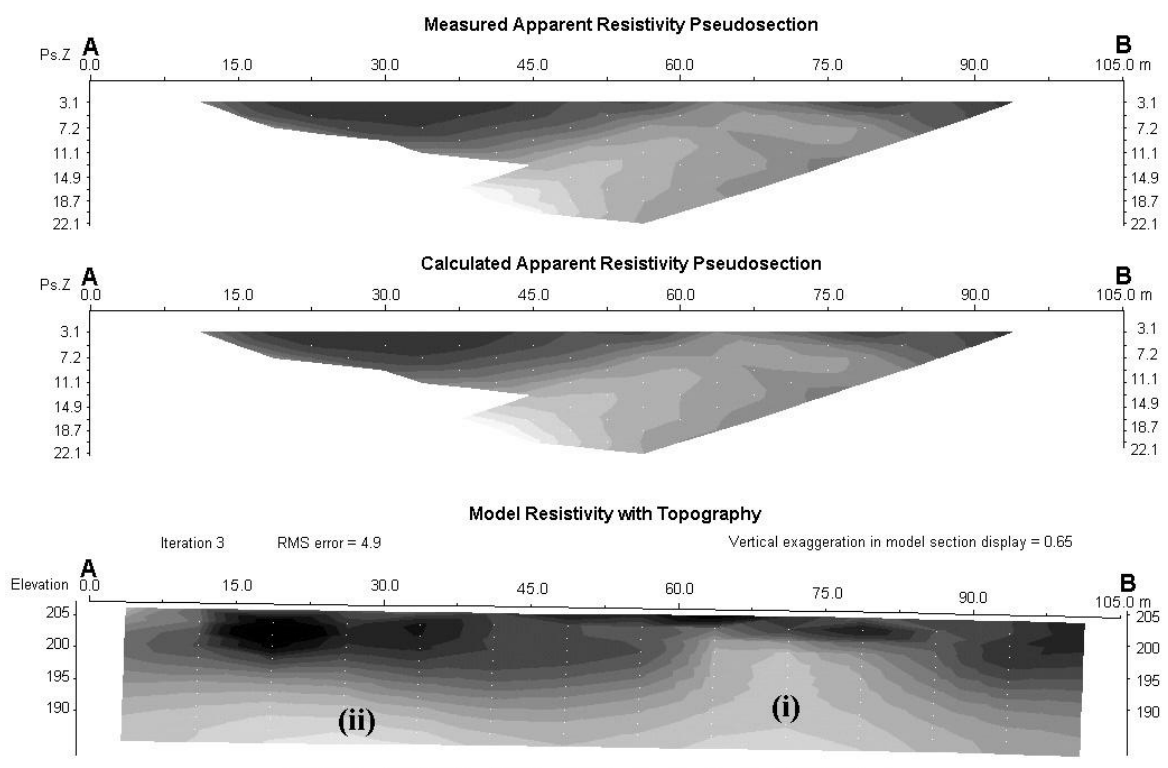

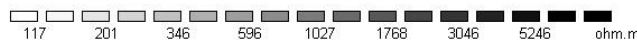

First electrode is located at $0.0 \mathrm{~m} \quad$ Last electrode is located at $105.0 \mathrm{~m} \quad$ Unit Electrode Spacing $=7.5 \mathrm{~m}$

Fig. 3 - Electrical resistivity profile P1 (A-B). Data field and 
interpreted model with topography.
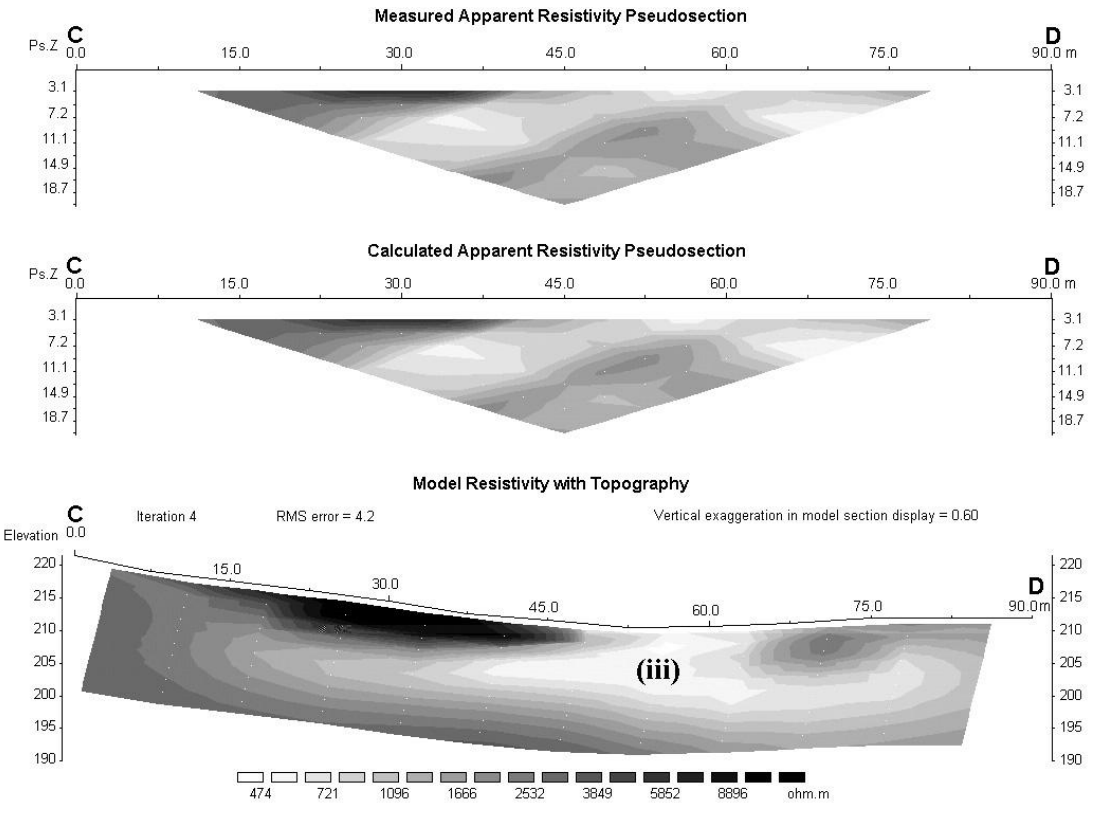

First electrode is locate $00 \mathrm{~m}$

Fig. 4 - Electrical resistivity profile P2 (C-D). Data field and interpreted model with topography.
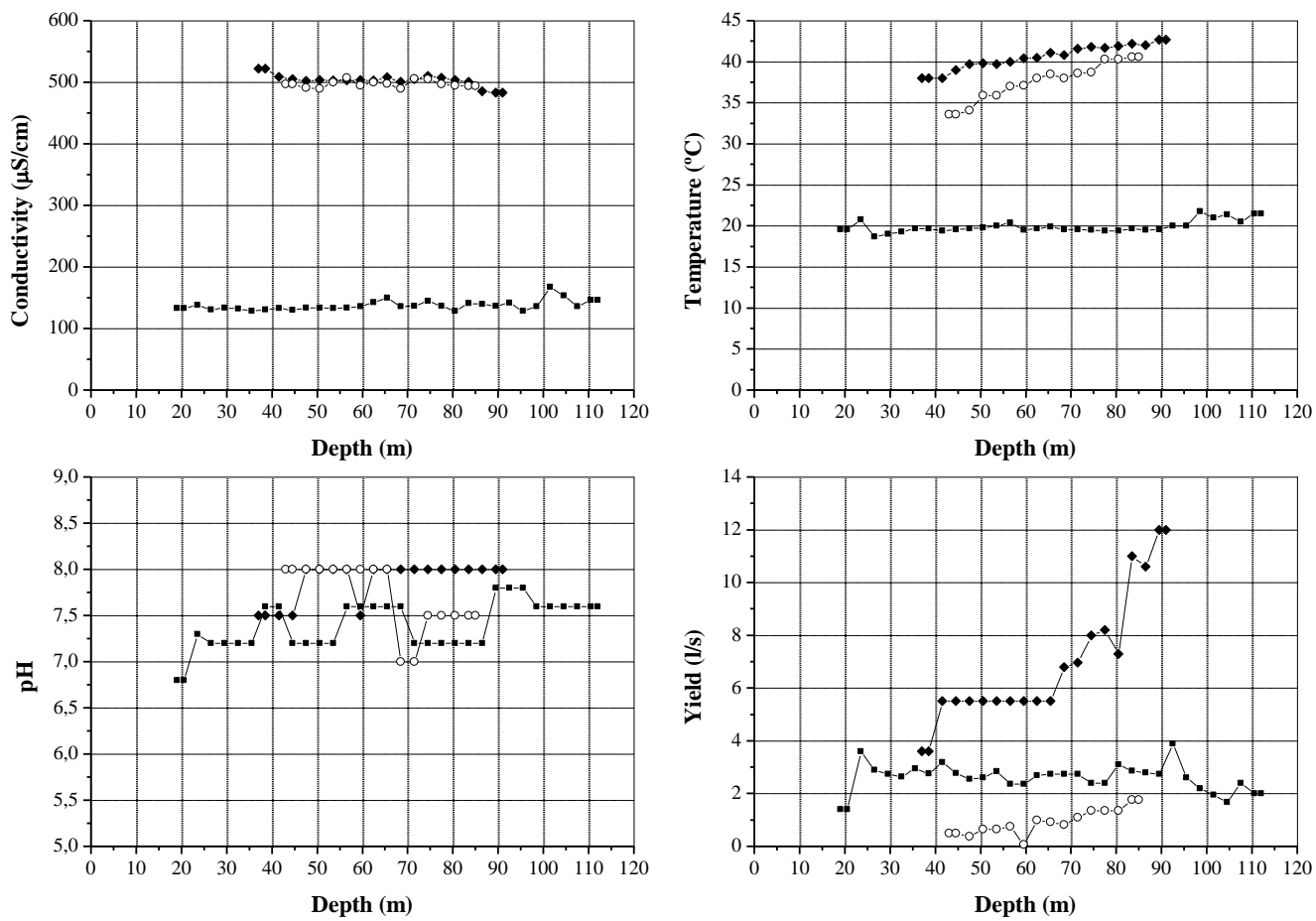

Fig. 5 - Field measurements for HDN1, HDN2 and HDN3 wells. 